[Agr. Biol. Chem., Vol. 34, No. 2, p. 222 226, 1970]

\title{
The Production of Phenylacetaldehyde from L-Phenylalanine in Tea Fermentation
}

\author{
By Ryoyasu SAIJo and Tadakazu TAKeo
}

Tea Research Station, Ministry of Agriculture and Forestry, Kanaya, Shizuoka

Received July 3, 1969

\begin{abstract}
Tea leaves macerated with L-phenylalanine generated rose like aroma. The gas chromatogram of the essential oil obtained from these leaves showed extremely large peak of phenylacetaldehyde. The evidence for degradation of L-phenylalanine to phenylacetaldehyde and carbon dioxide was given by the radioactive tracer experiment using L-phenylalanineU-14 C. The phenylacetaldehyde was presumed to be an intermediate product in tea fermentation from the data on the changes of the compound in tea fermentation process.
\end{abstract}

Phenylacetaldehyde ${ }^{1,2)}$ is considered as one of the important constituents for the quality of black tea because of its rose like aroma.

Bokuchava and Popov $^{31}$ pointed out the significance of amino acids in the formation of black tea aroma from the results that the addition of amino acids to aqueous solution of tea tannin, at $70^{\circ} \mathrm{C}$ for $12 \mathrm{hr}$, led to the development of characteristic aroma; Lphenylalanine produced rose like aroma. They suggested that these characteristic aroma were produced by the oxidation of the amino acids by the quinones present in tea tannin.

Nakabayashi" indicated that some kinds of carbonyl compounds were derived from the corresponding amino acids and quinone, oxidized products of tea polyphenols, mainly by Strecher degradation at the drying stage of black tea manufacture. This paper deals

1) T. Yamanishi, A. Kobayashi, H. Sato, A. Ohmura and H. Nakamura, Agr. Biol. Chem., 29, 1016 (1965).

2) R. Viani, F. Mueggler-Chavan, L. Vuataz, D. Reymond and R. H. Egli, Chimia (Aarau) 20 (1), 28 (1966) [C. A., 64, 10327 a (1966)].

3) M. A. Bokuchava and V.R. Popov, Doklady Akad. Nauk S. S.S.R. 99, 145 (1954) [C. A., 49, 3439c (1955)].

4) T. Nakabayashi, Nippon Nogeikagaku Kaishi, 32, 941 (1958). with determining if L-phenylalanine is the precursor of phenylacetaldehyde made in tea fermentation by radioactive tracer experiment.

\section{MATERIALS AND METHODS}

Materials. The young tea leaves, field-grown in summer, of the hybrid of the var. assamica named Benihomare were used for preparing essential oils and those of the var. assamica, green house-grown in winter, were used for the radioactive tracer experiments. All of the young leaves were consisted of three leaves and a bud. $5 \mu$-Ci L-phenylalanineU-14 C (specific activity $297 \mathrm{mCi} / \mathrm{mmole}$ ) was used as a radioactive tracer, after being diluted with $5 \mu$ moles Lphenylalanine (cold).

Method of fermentation and preparation of the essential oils. A hundred $\mathrm{g}$ of freshly Plucked leaves were withered on net for $16 \mathrm{hr}$ at room temperature. The withered leaves were rolled for $1 \mathrm{hr}$ with addition of $0.1 \mathrm{~g}$ of L-phenylalanine dissolved in $10 \mathrm{ml}$ water and fermented for $3 \mathrm{hr}$ at $25^{\circ} \mathrm{C}$. Instead of L-phenylalanine $\beta$-phenylethylalcohol was also added and fermented as the same way. The fermented leaves added nothing were prepared for comparison. Essential oils were prepared from the fermented leaves by the same procedure as described in the previous paper. ${ }^{5}$ )

5) R. Saijō and Y. Kuwabara, Agr. Biol. Chem., 31, 389 (1967). 
Gas chromatography. Gas chromatographic analysis was carried out by a Hitachi model KGL-2A gas chromatograph with a flame ionization detector. The column was $2 \mathrm{~m}$ in length, $4 \mathrm{~mm}$ internal diameter and packed with $23 \%$ Carbowax-6000 on Chromosorb W. The operation was conducted isothermally at $150^{\circ} \mathrm{G}$ with a helium flow rate of $30 \mathrm{ml} / \mathrm{min}$. The peak coincided with phenylacetaldehyde was trapped and 2,4-dinitrophenylhydrazone $(2,4-\mathrm{DNPH})$ was prepared by adding $5 \% 2$, 4-dinitrophenylhydrazine in phosphoric acid.

Experimental procedure with the use of radioactive $L$ phenylalanine. Three $\mathrm{g}$ of tea leaves withered for $16 \mathrm{hr}$ were macerated in a mortar for $5 \mathrm{~min}$ with $5 \mu \mathrm{Ci}$ L-phenylalanine-U-14 $\mathrm{C}$, and then fermented at $25^{\circ} \mathrm{C}$ under dark condition in Petri dish in which $2 \mathrm{ml}$ of $20 \% \mathrm{KOH}$ was placed for absorbing carbon dioxide and volatile acidic substance. The fermented leaves were killed by $50 \mathrm{ml}$ of boiling water and distilled in vacuo. The resultant was extracted with benzene.

Determination of carbon dioxide. The content of radioactive carbon dioxide was determined from the radioactive difference between $20 \% \mathrm{KOH}$ fraction and the supernatant which was obtained by removal of the precipitate of $\mathrm{BaCO}_{3}$.

Separation of non-volatile fraction. Non-volatile fraction was separated into soluble and non-soluble frac- tions by extraction with $200 \mathrm{ml}$ of boiling water. The soluble fraction was applied to Amberlite IR-120 $\left(\mathrm{H}^{+}\right)$column. The absorbed cationic fraction, after being eluted with $1 \mathrm{~N} \mathrm{NH}{ }_{4} \mathrm{OH}$, was further analyzed by paper chromatography of developing solvent with $n$-butanol-acetic acid-water $(4: 1: 2)$, and then $L$ phenylalanine remained was determined as the spot having $R f$ value of 0.62 .

Fractionation of volatile fraction and isolation of radioactive phenylacetaldehyde. After the benzene phase of volatile fraction was extracted with $3 \% \mathrm{HCl}$ and $5 \%$ $\mathrm{NaOH}$ to separate basic and acidic fractions respectively, 2,4-DNPH was prepared by adding 2,4-dinitrophenylhydrazine reagent and a little quantity of phenylacetaldehyde (cold) to the neutral benzene phase. The 2,4-DNPH precipitated was filtered off and washed with ethylalcohol. The precipitate was dissolved in a small volume of acetone, streaked on a thin layer plate of silica-gel (Wakogel B-5, $250 \mathrm{~m} \mu$ ) and developed with benzene-ligroin-ethylacetate $(6: 6: 1)$. Authentic phenylacetaldehyde 2,4-DNPH was developed as a marker and the radioactive zone was scraped off with a spatula, eluted by acetone and recrystallized repeatedly from ethanol-water.

Measurement of radioactivity. Radioactivity was measured by a Aloka $2 \pi$ gas flow counter, model JDC-104 B. Radio paper chromatograms were prepared by a Aloka $4 \pi$ paper chromatogram autoscanner, model PCS-2.

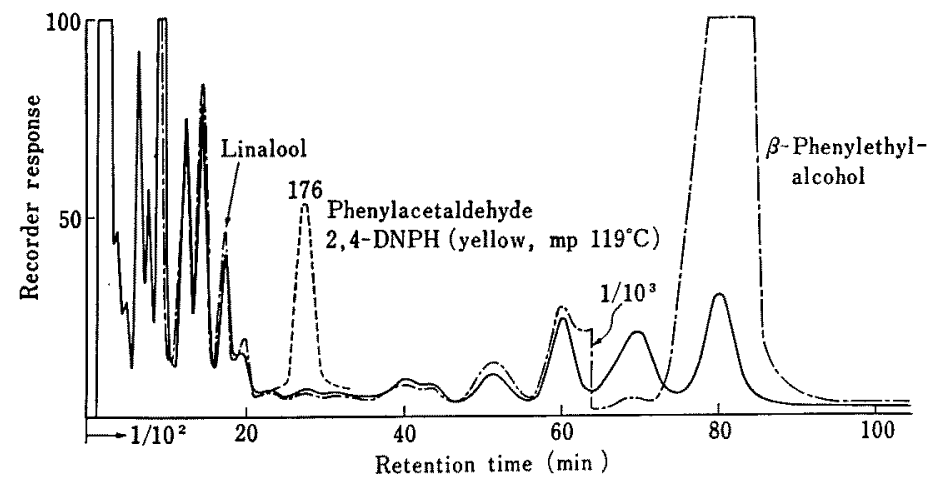

FIG. 1. The Comparison of the Essential Oils which were Obtained from Tea Leaves Fermented with or without Addition of L-Phenylalanine and $\beta$-Phenylethylalcohol.

Carbowax $6000,150^{\circ} \mathrm{C}, 25 \mathrm{ml} / \mathrm{min} \mathrm{He}, \mathrm{FID} \times 1 / 10^{2} \sim 1 / 10^{3}$

Normally fermented leaves (no addition)

-.....- Peak occured by addition of L-Phe.

.... Fermented leaves with addition of $\beta$-phenylethylalcohol. 


\section{RESULTS AND DISCUSSION}

Gas chromatography of the essential oils obtained from the fermented leaves

Immediately after tea leaves were rolled with L-phenylalanine, rose like aroma was generated from the leaves. The essential oils obtained from tea leaves rolled by three different treatments described in the method gave characteristic odor. These gas chromatograms were shown in Fig. 1.

The gas chromatogram of real line showed the typical pattern of fermented leaves. The peak $176^{*}$, as written in dotted line in the gas chromatogram, increased remarkably by the addition of L-phenylalanine to tea leaves. The gas chromatogram of broken line was almost the same as that of real line except the peak of $\beta$-phenylethylalcohol added. The substance of peak 176 had rose like aroma and its retention time coincided with that of phenylacetaldehyde. The 2, 4-DNPH made from the substance of peak 176 had $\mathrm{mp}$ $119^{\circ} \mathrm{C}$ and this melting point unchanged on mixture with an authentic specimen of phenylacetaldehyde 2, 4-DNPH. From these results it was thought that L-phenylalanine might produce phenylacetaldehyde during tea fermentation and that $\beta$-phenylethylalcohol could not be oxidized to phenylacetaldehyde under the condition of tea fermentation.

The distribution of radioactivity in tea leaves fermented with addition of $L-p$ henylalanine- $U-{ }^{19} \mathrm{C}$ The volatile and non-volatile fractions from tea leaves fermented with L-phenylalanine$\mathrm{U}-{ }^{14} \mathrm{C}$ for 0.5 and $1.5 \mathrm{hr}$ were fractionated, and then the distribution of radioactivity in each fraction was measured. The result was summerized in Table I.

These results showed that most of L-phenylalanine remained unchanged and that approximately one fourth of L-phenylalanine changed to other substance.

Amberlite IR-120 absorbed fraction was the cationic substance except L-phenylalanine$\mathrm{U}-{ }^{14} \mathrm{C}$.

Amberlite IR-120 not absorbed fraction was further analysed and found to be precipitated by lead acetate. In volatile fractions radioactivity was detected in carbon dioxide, acid and carbonyl fractions. The carbonyl radioactivity was the highest. In comparison with two fermentation stages radioactivity in $1.5 \mathrm{hr}$ was slightly higher than in $0.5 \mathrm{hr}$.

Table I. Fate of L-Phenylalanine-U-14C IN Tea Fermentation

\begin{tabular}{|c|c|c|c|}
\hline & \multirow[t]{2}{*}{ Fraction } & \multicolumn{2}{|c|}{$\begin{array}{l}\text { Distribution of radio- } \\
\text { activity } \times 10^{3} \mathrm{cpm}(\%) \\
\text { Fermentation time (hr) }\end{array}$} \\
\hline & & 0.5 & 1.5 \\
\hline \multirow{4}{*}{$\begin{array}{l}\text { Non-volatile } \\
\text { Soluble }\end{array}$} & L-Phe-14C (remained) & $3,103.7(78.5)$ & $3,001.6(77.5)$ \\
\hline & Amberlite IR-120 abs. & $559.3(14.2)$ & $539.5(13.9)$ \\
\hline & Amberlite IR-120 not abs. & $178.6(4.5)$ & $197.6(5.1)$ \\
\hline & Non-soluble & $41.9(1.1)$ & $52.6(1.4)$ \\
\hline \multirow{5}{*}{ Volatile } & $\mathrm{CO}_{2}$ & $5.5(0.1)$ & $6.0(0.2)$ \\
\hline & Basic & $0 \quad(0)$ & $0 \quad(0)$ \\
\hline & Acidic & $4.6(0.1)$ & $5.0(0.1)$ \\
\hline & Carbonyl & $58.9(1.5)$ & $68.9(1.8)$ \\
\hline & Carbonyl-free neutral & $0 \quad(0)$ & $0 \quad(0)$ \\
\hline
\end{tabular}

* Peak number shows the relative retention time to linalool (linalool $=100$ ). 
The evidence of radioactivity existed in phenylacetaldehyde

Figure 2 showed thin layer chromatogram of volatile carbonyl compounds 2, 4-DNPH and radioactivity on the chromatogram.

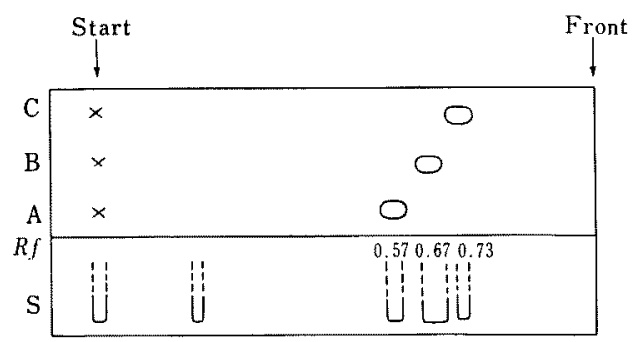

Redioactivity (cpm)

\begin{tabular}{|l|l|l|l|l|l|l|l|l|l|l|}
\hline 23 & 5 & 10 & 2 & 0 & 7 & 88 & 103 & 68 & 2 & 5 \\
\hline
\end{tabular}

FIG. 2. Thin-layer Chromatography of 2, 4-DNPH Separated from Radioactive Volatile Compounds of Fermented Leaves.

S : Sample

A : Authentic acetaldehyde 2, 4-DNPH

B : Authentic phenylacetaldehyde 2,4-DNPH

$\mathrm{C}$ : Authentic benzaldehyde 2, 4-DNPH

Developing solvent of benzene-ligroin-ethylacetate $(6: 6: 1)$.

Radioactivity appeared to the zone of 0.67 of $R f$ value which corresponded to that of authentic phenylacetaldehyde 2, 4-DNPH. The specific radioactivity of 2, 4-DNPH obtained from the zone was measured for three time crystallizations, the values being $750,800,730 \mathrm{cpm} / \mathrm{mg}$ respectively. From these nearly constant values it was evidenced that radioactive carbon of $\mathrm{L}$-phenylalanine- $\mathrm{U}-{ }^{14} \mathrm{C}$ really incorporated into phenylacetaldehyde.

\section{Analysis of volatile acidic fraction}

Radio paper chromatography of the volatile acids was done by using the developing solvent of $n$-butanol saturated with $1.5 \mathrm{~N}$ ammonium hydroxide. ${ }^{61}$ The spots of 0.22

6) E. Lederer and M. Lederer, "Chromatography," Elsevier Publishing Co., 1954, p. 123 124. and 0.34 of $R f$ value were recognized but, the amounts were too small to identify. Both of them did not correspond with $\mathrm{C}_{1}$ or $\mathrm{C}_{2}$ acids. It was supposed, therefore, that these were larger than $C_{3}$ acid. Since $C_{1}$ acid was not existed, $\mathbf{C}_{\mathbf{1}}$ compound was determined as carbon dioxide alone.

Changes of phenylacetaldehyde and carbon dioxide during tea fermentation

These results were shown in Fig. 3. The assay for phenylacetaldehyde was made by measuring volatile carbonyl compounds, since

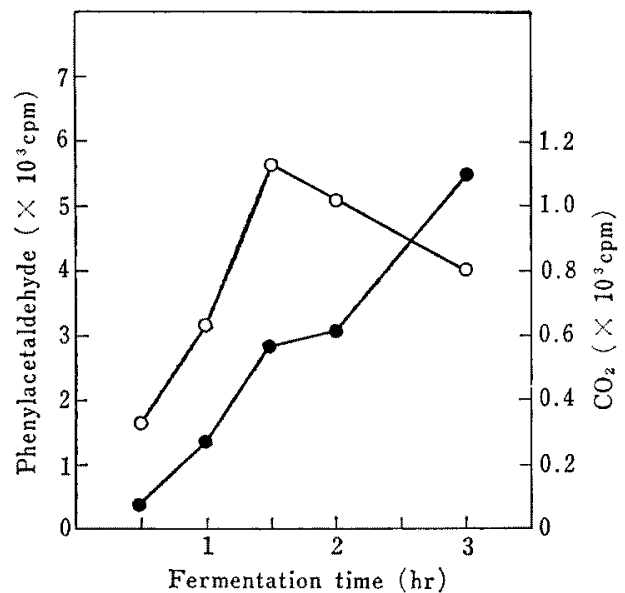

FIG. 3. Changes of Phenylacetaldehyde and Carbon Dioxide during Tea Leave Fermentation.

O Phenylacetaldehyde, Carbon dioxide.

most of volatile carbonyl compounds could be phenylacetaldehyde from the results mentioned above. As shown in Fig. 3, carbon dioxide increased contineously, however phenylacetaldehyde reached to a maximum point, at $1.5 \mathrm{hr}$ fermentation time, and then decreased. These findings suggested that synthesized phenylacetaldehyde was also degraded into other substances during black tea fermentation.

On the other hand theoretical ratio of phenylacetaldehyde to carbon dioxide, as the breakdown products from L-phenylalanine, 
is 8 to 1 , the measurement values are ap- intermediate products in black tea fermentaproximately satisfactory at the first stage of tion.

fermentation. From these results the breakdown of L-phenylalanine is supposed to be Strecker degradation. The change of phenylacetaldehyde is just like that of trans-2-hexen1-al reported previously, ${ }^{5 /}$ therefore, these two carbonyl compounds are presumed to be an

Acknowledgements. The authors wish to express their gratitude to Dr. I. Uritani, University of Nagoya, for his valuable suggestions. Thanks are also due to Mr. Iwasa, Tea Research Station, M.A.F. for his kind help in technique of radioactive tracer analysis. 